\title{
The Autonomic Brain: An Activation Likelihood Estimation Meta-Analysis for Central Processing of Autonomic Function
}

\author{
Florian Beissner, ${ }^{1,3}$ Karin Meissner, ${ }^{2}$ Karl-Jürgen Bär, ${ }^{1}$ and Vitaly Napadow ${ }^{3}$ \\ ${ }^{1}$ Pain and Autonomics Integrative Research, Department of Psychiatry and Psychotherapy, Jena University Hospital, 07743 Jena, Germany, ${ }^{2}$ Institute of \\ Medical Psychology, Ludwig-Maximilians-University, 80336 Munich, Germany, and ${ }^{3}$ Athinoula A. Martinos Center for Biomedical Imaging, Department of \\ Radiology, Massachusetts General Hospital, Charlestown, Massachusetts 02129
}

The autonomic nervous system (ANS) is of paramount importance for daily life. Its regulatory action on respiratory, cardiovascular, digestive, endocrine, and many other systems is controlled by a number of structures in the CNS. While the majority of these nuclei and cortices have been identified in animal models, neuroimaging studies have recently begun to shed light on central autonomic processing in humans. In this study, we used activation likelihood estimation to conduct a meta-analysis of human neuroimaging experiments evaluating central autonomic processing to localize (1) cortical and subcortical areas involved in autonomic processing, (2) potential subsystems for the sympathetic and parasympathetic divisions of the ANS, and (3) potential subsystems for specific ANS responses to different stimuli/tasks. Across all tasks, we identified a set of consistently activated brain regions, comprising left amygdala, right anterior and left posterior insula and midcingulate cortices that form the core of the central autonomic network. While sympatheticassociated regions predominate in executive- and salience-processing networks, parasympathetic regions predominate in the default mode network. Hence, central processing of autonomic function does not simply involve a monolithic network of brain regions, instead showing elements of task and division specificity.

\section{Introduction}

The autonomic nervous system (ANS) is involved in virtually every aspect of our daily life. The motor arm of the ANS regulates physiology within a variety of systems including respiratory, cardiac, vasomotor, digestive, and endocrine (Jänig, 2008). This ANS outflow calibrates bodily reactions with contextually adaptive behavior to meet the metabolic demands of motor, emotional, and cognitive challenges (e.g., Thayer and Lane, 2000; Critchley, 2005). Some of the most important integrative control centers for ANS functions are located in the brainstem and have been studied extensively in animals. Much less, however, is known about cerebral and cerebellar regions involved in autonomic regulation. Nevertheless, a central autonomic network (CAN) has been proposed based on observations from animal experiments using electrical stimulation and from tracer studies (Cechetto and Saper, 1990; Benarroch, 1993; Verberne and Owens, 1998; Saper, 2002).

Since the advent of noninvasive brain-imaging methods, a direct measurement of such regions has become possible in hu-

\footnotetext{
Received March 13, 2013; revised April 26, 2013; accepted May 4, 2013.

Author contributions: F.B. and V.N. designed research; F.B., K.M., K.-J.B., and V.N. performed research; F.B., K.M., and V.N. analyzed data; F.B., K.M., K.-J.B., and V.N. wrote the paper.

This work was supported by German Research Foundation Grant BE4677/1-1 (F.B.) and National Center for Complementary and Alternative Medicine Grants R01-AT004714, R01-AT005280, and P01-AT006663 and NIDDK Grant R21-DK097499 (V.N.).

The authors declare no competing financial interests.

Correspondence should be addressed to Florian Beissner, Athinoula A. Martinos Center for Biomedical Imaging, Department of Radiology, Massachusetts General Hospital, Harvard Medical School, 149 13th Street, Room 2316, Charlestown, MA 02129. E-mail: florian@nmr.mgh.harvard.edu.

DOI:10.1523/JNEUROSCI.1103-13.2013

Copyright $\odot 2013$ the authors $\quad 0270-6474 / 13 / 3310503-09 \$ 15.00 / 0$
}

mans. A growing number of studies has investigated the role of these regions in autonomic control during cognitive, affective, and motor tasks, as well as during somatosensory and other modes of bodily stimulation. Based on some of their findings, the CAN has been approached from different perspectives. Some authors have highlighted the independent roles of single CAN regions, like the ventromedial prefrontal cortex (vmPFC), the anterior cingulate cortex (ACC), and the insula (Critchley et al., 2011), while others (Thayer and Lane, 2000) have emphasized similarities between the CAN and other theoretical constructs, like the anterior executive region of Devinsky et al. (1995) or the neural substrate of Damasio's "somatic marker hypothesis" (Damasio 1998). A comprehensive interpretation of the results obtained by imaging studies of autonomic CNS regions, however, is hampered by their large heterogeneity. Thus, a systematic review of neuroimaging studies assessing the CAN in humans seems timely.

We chose the meta-analytic activation likelihood estimation (ALE) method (Turkeltaub et al., 2002) to evaluate commonly activated regions across multiple studies. While a recent metaanalysis focused on assessing brain activity associated with heart rate variability (HRV) (Thayer et al., 2012), our aim was to perform a more comprehensive analysis, including all studies that had measured an autonomic outflow metric in conjunction with neuroimaging data. We evaluated the CAN across three task categories and two ANS outflow metrics. We also investigated the hypothesis that different subregions of the CAN are specifically involved in the sensory and motor control of the ANS when humans are responding to specific stimuli. Furthermore, the well-known dichotomy of a sympathetic and parasympathetic 
Table 1. Included ANS-fMRI studies with their stimuli and metrics

\begin{tabular}{|c|c|c|c|c|c|c|c|c|}
\hline & \multirow[b]{2}{*}{$n$} & \multirow[b]{2}{*}{ Foci } & \multicolumn{3}{|c|}{ Stimuli/tasks } & \multicolumn{3}{|c|}{ Metrics } \\
\hline & & & Affective & $\begin{array}{l}\text { Somatosensory- } \\
\text { motor }\end{array}$ & Cognitive & EDA & HFHRV & other \\
\hline Fredrikson et al. (1995) & 16 & 11 & & & & $x$ & & $\times$ \\
\hline Hsieh et al. (1996) & 4 & 10 & & $\times$ & & & & $\times$ \\
\hline Critchley et al. (2000a) & 6 & 34 & & $x$ & $x$ & & & $\times$ \\
\hline Critchley et al. (2000b) & 6 & 13 & & & $\times$ & $\times$ & & \\
\hline Redouté et al. (2000) & 9 & 7 & & & & & & $\times$ \\
\hline Williams et al. (2001) & 11 & 4 & $x$ & & & $x$ & & \\
\hline Ito et al. (2002) & 11 & 12 & & & & & & $\times$ \\
\hline Critchley et al. (2003) & 6 & 32 & & $\times$ & $\times$ & & $\times$ & \\
\hline Kuniecki et al. (2003) & 16 & 14 & $x$ & & & & & $\times$ \\
\hline Nagai et al. (2004b) & 8 & 38 & & & & $x$ & & \\
\hline Petrovic et al. (2004) & 7 & 2 & & $x$ & & $x$ & & \\
\hline Williams et al. (2004) & 22 & 10 & $x$ & & & $x$ & & \\
\hline Critchley et al. (2005) & 15 & 3 & & & $\times$ & & & $\times$ \\
\hline Kimmerly et al. (2005) & 8 & 12 & & & & & & $\times$ \\
\hline Knight et al. (2005) & 9 & 13 & & & $\times$ & $\times$ & & \\
\hline Lemche et al. (2006) & 11 & 6 & & & & $\times$ & & \\
\hline Macey et al. (2006) & 11 & 19 & & & & & $\times$ & $\times$ \\
\hline Nicotra et al. (2006) & 14 & 6 & $\times$ & & & & & $\times$ \\
\hline Koelsch et al. (2007) & 41 & 4 & $x$ & & & & $\times$ & \\
\hline Lagopoulos et al. (2007) & 10 & 10 & $\times$ & & & $\times$ & & \\
\hline Gamer et al. (2007) & 14 & 5 & & & $\times$ & $\times$ & & \\
\hline Marci et al. (2007) & 10 & 12 & $\times$ & & & $\times$ & $\times$ & $\times$ \\
\hline Napadow et al. (2008) & 7 & 13 & & $\times$ & & & $\times$ & \\
\hline Wendt et al. (2008) & 32 & 7 & $x$ & & & $\times$ & & \\
\hline Evans et al. (2009) & 14 & 12 & & & $\times$ & & & $\times$ \\
\hline Harrison et al. (2009) & 14 & 6 & & & & & & $\times$ \\
\hline Kozel et al. (2009) & 31 & 8 & & & $\times$ & $\times$ & & \\
\hline Matsunaga et al. (2009) & 12 & 16 & $x$ & & & & $x$ & \\
\hline Mériau et al. (2009) & 23 & 8 & $x$ & & & $x$ & & \\
\hline Mobascher et al. (2009) & 12 & 11 & & $\times$ & & $x$ & & \\
\hline Suzuki et al. (2009) & 12 & 26 & & $x$ & & & & $\times$ \\
\hline Urry et al. (2009) & 26 & 2 & $x$ & & & $\times$ & & $\times$ \\
\hline Ziegler et al. (2009) & 26 & 1 & & & & & & $\times$ \\
\hline Fechir et al. (2010a) & 16 & 22 & & & $\times$ & $\times$ & & $\times$ \\
\hline Fechir et al. (2010b) & 10 & 3 & & & & & & $\times$ \\
\hline Harrison et al. (2010) & 12 & 14 & $x$ & & & & & $\times$ \\
\hline Piché et al. (2010) & 14 & 2 & & $\times$ & & $\times$ & & \\
\hline Goswami et al. (2011) & 12 & 8 & & $\times$ & & & $x$ & $\times$ \\
\hline Maihöfner et al. (2011) & 12 & 56 & & $\times$ & & & & $\times$ \\
\hline Nugent et al. (2011) & 7 & 24 & & $\times$ & $\times$ & & $\times$ & $\times$ \\
\hline Beissner et al. (2012) & 19 & 5 & & $\times$ & & & & $\times$ \\
\hline Gray et al. (2012) & 21 & 11 & & & $\times$ & & & $\times$ \\
\hline Napadow et al. (in press) & 18 & 39 & & $x$ & & $x$ & & $\times$ \\
\hline Total & 615 & 571 & 12 & 13 & 11 & 19 & 8 & 25 \\
\hline
\end{tabular}

division of the ANS (Langley, 1903) that emanates from thoracolumbal and craniosacral regions of the CNS, respectively, is largely based on peripheral anatomy, but has been difficult to establish for higher centers of the CNS. Therefore, we aimed to resolve CAN subnetworks specific to these two important subdivisions of the ANS, and to gain insight into which subregions of the sympathetic and parasympathetic CAN subdivisions are associated with the performance of specific tasks or responses to specific stimuli.

\section{Materials and Methods}

Study selection. Our aims for the ALE meta-analysis were achieved by first identifying functional brain imaging studies of healthy subjects that had measured one or more peripheral autonomic signals. To identify relevant studies, we performed a literature search in Medline using a logical conjunction of the following three search terms: (1) a functional brain imaging modality, (2) the most relevant adjectives related to the autonomic nervous system, and (3) autonomic signals typically measured in a neuroimaging environment. Functional brain imaging modalities included positron emission tomography (PET), single-photon emission computed tomography (SPECT), magnetoencephalography (MEG), and functional magnetic resonance imaging (fMRI). For example, the search

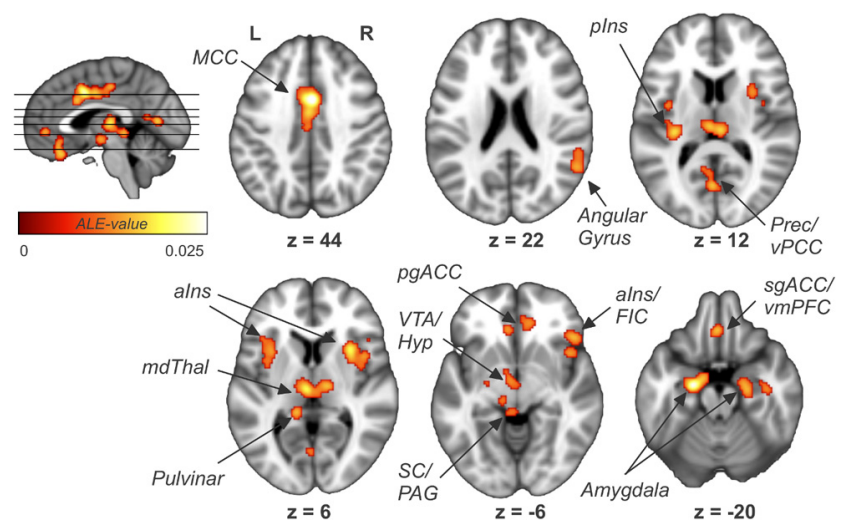

Figure 1. Results of the pooled analyses of all studies showing general brain regions involved in autonomic processing. Prec, Precuneus; VPCC, ventral posterior cingulate cortex; mdThal, mediodorsal thalamus; pgACC, pregenual ACC; VTA, ventral tegmental area; Hyp, hypothalamus; SC, superior colliculus; PAG, periaqueductal gray; FIC, frontoinsular cortex; L, left; $R$, right.

Table 2. ALE clusters of the pooled analysis of all studies

\begin{tabular}{|c|c|c|c|c|c|c|}
\hline \multirow[b]{2}{*}{ Anatomical region } & \multirow[b]{2}{*}{ Size $\left(\mathrm{mm}^{3}\right)$} & \multirow[b]{2}{*}{$L / R$} & \multirow{2}{*}{$\begin{array}{l}\text { Max. ALE } \\
\text { score }\end{array}$} & \multicolumn{3}{|c|}{$\begin{array}{l}\text { MNI coordinates (in } \\
\mathrm{mm} \text { ) }\end{array}$} \\
\hline & & & & $x$ & $y$ & $z$ \\
\hline Midcingulate Cortex & 7864 & $L / R$ & 0.0283 & 2 & 10 & 40 \\
\hline $\begin{array}{l}\text { Thalamus (medial-dorsal nucleus, } \\
\text { pulvinar), Superior colliculus/ } \\
\text { periaqueductal gray }\end{array}$ & 6024 & $L / R$ & 0.0191 & -4 & -16 & 8 \\
\hline $\begin{array}{l}\text { Amygdala, hypothalamus, ventral } \\
\text { tegmental area }\end{array}$ & 4736 & L & 0.0271 & -20 & -6 & -18 \\
\hline Anterior insula & 3128 & $\mathrm{R}$ & 0.0193 & 32 & 18 & 0 \\
\hline Amygdala, hippocampal formation & 2216 & $\mathrm{R}$ & 0.0160 & 20 & -6 & -18 \\
\hline Interior insula & 2040 & L & 0.0152 & -36 & 22 & 0 \\
\hline $\begin{array}{l}\text { Ventromedial prefrontal cortex, } \\
\text { subgenual anterior cingulate } \\
\text { cortex }\end{array}$ & 1896 & $\mathrm{~L} / \mathrm{R}$ & 0.0168 & -4 & 36 & -24 \\
\hline Pregenual anterior cingulate cortex & 1504 & $\mathrm{~L} / \mathrm{R}$ & 0.0143 & -2 & 52 & -2 \\
\hline upramarginal gyrus & 1344 & $\mathrm{R}$ & 0.0144 & 56 & -48 & 22 \\
\hline $\begin{array}{l}\text { Ventral posterior cingulate cortex, } \\
\text { precuneous cortex, lingual gyrus }\end{array}$ & 1152 & $\mathrm{~L} / \mathrm{R}$ & 0.0169 & -2 & -64 & 10 \\
\hline Posterior insula & 1064 & $\mathrm{~L}$ & 0.0173 & -32 & -20 & 12 \\
\hline Frontoinsular cortex & 1040 & $\mathrm{R}$ & 0.0151 & 46 & 32 & -6 \\
\hline
\end{tabular}

There were 43 studies, 616 subjects, 569 foci, $9.75 \mathrm{~mm}$ FWHM, and 1000 permutations. $p<0.01$ is the clusterforming threshold; $p<0.05$ is the cluster threshold. L, Left; $R$, right.

term for fMRI studies was "('fMRI' OR 'functional magnetic resonance imaging') AND ('autonomic' OR 'sympathetic' OR 'parasympathetic' OR 'vagal' OR 'vagus') AND ('heart rate' OR 'respiration' OR 'skin conductance response' OR 'skin response' OR 'pupil' OR 'skin temperature' OR 'blood pressure' OR 'electrogastrography').” In the other three searches, "fMRI" was replaced by one of the remaining imaging modalities (in full and abbreviation).

The literature search was performed on March 8, 2012, and identified 350 studies for fMRI, 125 for PET, 10 for MEG, and 90 for SPECT. All studies subsequently underwent a selection process consisting of reading the articles' methods sections and applying the following inclusion criteria: (1) functional brain images and autonomic measures were acquired in the same experimental session; (2) autonomic measures were used in the analysis for reasons other than physiological noise correction; (3) only healthy subjects were studied or their data were analyzed separately from patients'; (4) peak coordinates of group-level activations were reported; and (5) image acquisition included at least cerebral and cerebellar cortex and the analysis was not restricted to predefined regions of interest.

Following this selection process, 43 studies met the inclusion criteria (32 fMRI, 11 PET, no MEG, no SPECT) and are listed in Table 1. The 


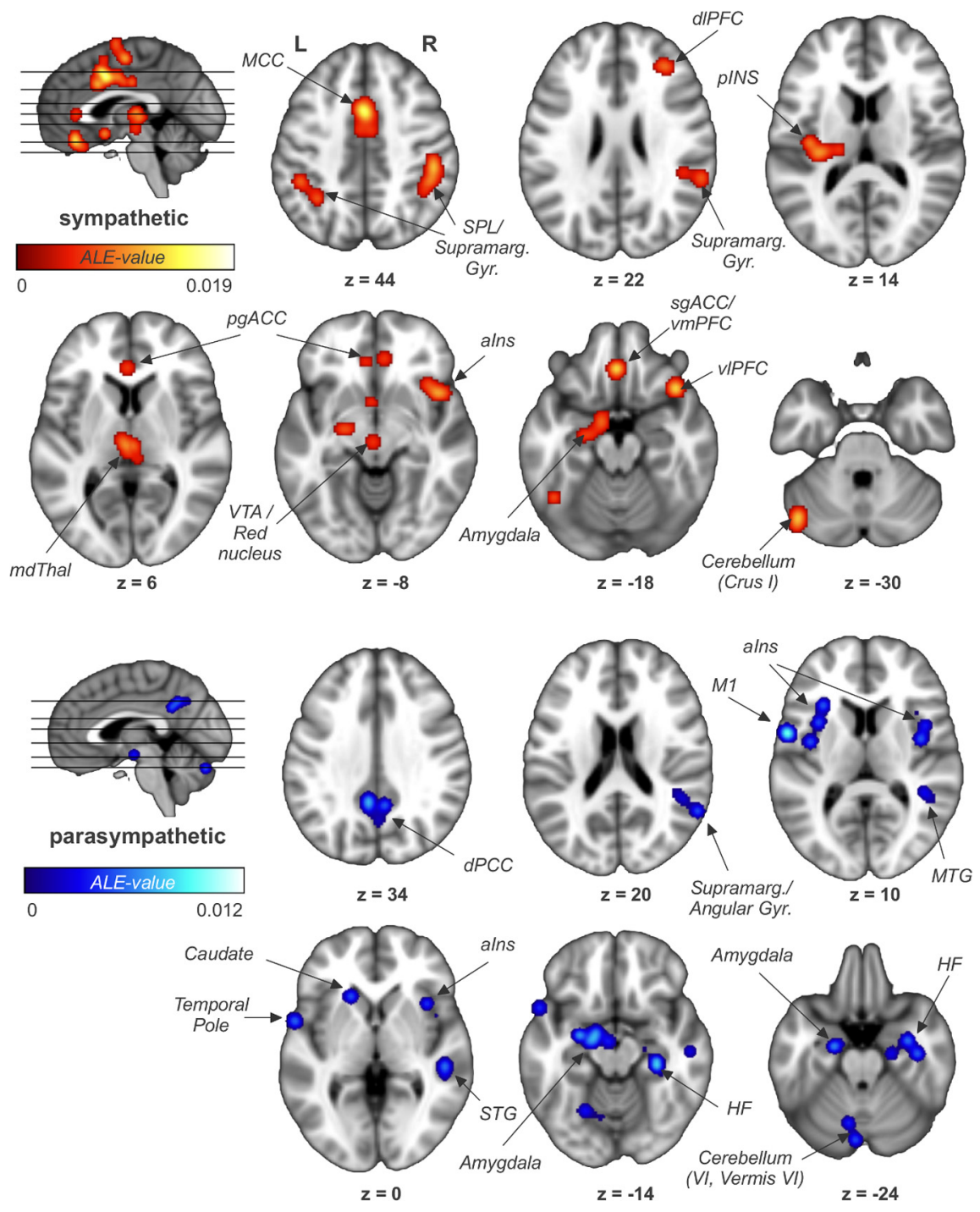

Figure 2. Brain areas associated with sympathetic and parasympathetic regulation as assessed by electrodermal activity and high-frequency heart rate variability. pgACC, Pregenual ACC; mdThal, mediodorsal thalamus; VTA, ventral tegmental area; M1, primary motor cortex; MTG, medial temporal gyrus; STG, superior temporal gyrus; L, left; $R$, right.

overall number of subjects was 615 (303 male, 252 female, 60 unclear from papers' descriptions) contributing 571 activation foci to the ALE analysis. Coordinates were extracted for each of these studies and entered into the ALE analysis.

The methods used to include autonomic recordings in the analyses of the functional imaging data were very diverse. However, the vast majority of studies either correlated time courses of autonomic signals directly with voxel time courses of the imaging data (23 studies) or used autonomic recordings to confirm that their stimuli modulated autonomic outflow (13 studies). The remaining seven studies either used parametric designs, where stimulus time courses were weighted by the intensity of the elicited ANS reaction, or conjunction designs, where the overlap of stimulus- and ANS-related activation clusters was assessed.

Tasks and divisions. Studies were categorized under two main aspects, namely, (1) tasks and stimuli (henceforth called "tasks") used to elicit an autonomic reaction and (2) the autonomic division predominantly driving the autonomic signal measured in the experiment (i.e., sympathetic or parasympathetic).

For the first aspect, three categories were formed: (1) "cognitive" for cognitively difficult or stressful tasks, like stroop, color word interference, or $n$-back tasks, but also deception or guilty knowledge tasks known to modulate the autonomic nervous system; (2) "affective" for emotional (appetitive or aversive) videos, pictures, music, or words, but also fear conditioning tasks; and (3) "somatosensorymotor" for handgrip tasks, tactile stimulation, acupuncture, and various pain induction methods.

For the second aspect involving the divisions of autonomic outflow, two categories were formed: (1) "sympathetic" for studies using electrodermal activity (EDA) or related metrics for skin conductivity (Venables, 1991), like galvanic skin response, skin conductance response, as well as their latencies and derivatives, and (2) "parasympathetic" for studies using the high-frequency spectral component of heart rate variability (HF-HRV) (Acharya et al., 2006). Although several metrics were used in the original studies, we chose to include only EDA and HF-HRV due to their clear interpretability in terms of representing the sympathetic and parasympathetic division of the autonomic nervous system: EDA is generally considered a purely sudomotor, sympathetic metric (Venables, 1991), whereas HF-HRV is regarded as a purely cardiovagal, parasympathetic metric (Acharya et al., 2006). It should also be mentioned that preejection period and muscle sympathetic nerve activity (MSNA) are unequivocal sympathetic measures, too, but no studies using these methods met our inclusion criteria. All studies were classified by two of the authors (F.B. and V.N.) and, if possible, allocated to one or more categories. This process yielded 11 studies for cognitive, 12 for affective, 13 for somatosensory-motor, 19 for sympathetic, and 8 for parasympathetic (Table 1).

To ensure independence of tasks and divisions (e.g., studies with cognitive tasks did not all cluster to include sympathetic metrics), the Freeman-Halton extension of the Fisher exact probability for a two-by-three contingency table was calculated. Its nonsignificance $(p=$ $0.30)$ suggested meaningful independent analysis of tasks and divisions.

ALE. We used activation likelihood estimation (Turkeltaub et al., 2002), a voxel-based meta-analysis tool, to test for commonly activated regions across studies. All ALE-related calculations were carried out in GingerALE 2.3 (http://www.brainmap.org/ale/; Research Imaging Center, University of Texas, San Antonio, TX) using the nonadditive ALE algorithm (Turkeltaub et al., 2012). For conjunction analyses (see below, Conjunction analyses), we additionally used the FSLMATHS and CLUSTER tools of FSL 5.0.1 (http://fsl.fmrib.ox.ac.uk/; FMRIB, Oxford, UK).

Because some studies reported coordinates in Talairach space, whereas others (the majority) in Montreal Neurological Institute (MNI) space, coordinates reported in Talairach space by any included study were transformed to MNI space using the inverse of the icbm2tal transform (Lancaster et al., 2007), before the ALE analysis.

The ALE procedure consisted of the following steps: (1) modeling of single-study activation foci as peaks of three-dimensional Gaussian probability densities with subject-based full-width at half-maximum values (Eickhoff et al., 2009); (2) summation of probability densities to produce a statistical map estimating the likelihood of activation at each voxel; (3) thresholding of this ALE map based on the null hypothesis of a uniform distribution of foci; (4) correcting for multiple comparisons by permutation-based thresholding of the maximum cluster size (Friston et al., 1994).

We used a cluster-forming threshold of $p<0.05$ and a cluster-level threshold of $p<0.05$ for all tests except Analysis 1, where significantly higher power involved in combining all 43 studies allowed for a threshold 


\begin{tabular}{|c|c|c|c|c|c|c|}
\hline \multirow[b]{2}{*}{ Anatomical region } & \multirow[b]{2}{*}{$\mathrm{L} / \mathrm{R}$} & \multirow[b]{2}{*}{ Size $\left(\mathrm{mm}^{3}\right)$} & \multirow[b]{2}{*}{ Max. ALE score } & \multicolumn{3}{|c|}{ MNI coordinates (in mm) } \\
\hline & & & & $x$ & $y$ & $z$ \\
\hline \multicolumn{7}{|l|}{ Sympathetic } \\
\hline Midcingulate cortex, paracingulate cortex, supplementary motor area & $L / R$ & 15,408 & 0.0190 & 0 & 10 & 40 \\
\hline Amygdala, subgenual anterior cingulate cortex, nucleus accumbens, caudate, hippocampal formation & $\mathrm{L}$ & 4784 & 0.0114 & -20 & -8 & -12 \\
\hline Ventromedial prefrontal cortex, pregenual/subgenual anterior cingulate cortex & $L / R$ & 4384 & 0.0129 & -2 & 38 & -18 \\
\hline Anterior insula, ventrolateral prefrontal cortex & $\mathrm{R}$ & 3912 & 0.0125 & 44 & 18 & -6 \\
\hline Secondary somatosensory cortex, posterior insula, putamen & $\mathrm{L}$ & 3176 & 0.0099 & -32 & -20 & 14 \\
\hline Cerebellum (lobulus crus I) & $\mathrm{L}$ & 3112 & 0.0122 & -46 & -66 & -28 \\
\hline Dorsolateral prefrontal cortex & $\mathrm{R}$ & 2984 & 0.0088 & 20 & 36 & 34 \\
\hline \multicolumn{7}{|l|}{ Parasympathetic } \\
\hline Hippocampal formation & $\mathrm{R}$ & 8416 & 0.0096 & 30 & -22 & -16 \\
\hline Amygdala, ventral tegmental area, hypothalamus & $\mathrm{L}$ & 5784 & 0.0124 & -20 & -6 & -18 \\
\hline Cerebellum (lobuli VI and vermis VI) & $\mathrm{L}$ & 3960 & 0.0070 & -10 & -62 & -20 \\
\hline Anterior insula & $\mathrm{R}$ & 3752 & 0.0072 & 40 & 2 & 12 \\
\hline
\end{tabular}

There were 19 studies, 296 subjects, and 172 foci, $9.57 \mathrm{~mm}$ FWHM, for EDA; 8 studies, 106 subjects, and 94 foci, $10.00 \mathrm{~mm}$ FWHM, for HF-HRV; and 1000 permutations. $p<0.05$ is the cluster-forming threshold and the cluster threshold. L, Left; R, right.

of $p<0.01$ to be used for cluster forming, providing for greater localizing power. The number of permutations was 1,000 for all calculations of simple ALE maps.

The following ALE meta-analyses were calculated. Analysis 1 is a pooled analysis of all studies, independent of their categorization to form a group map of brain areas generally involved in autonomic regulation. This can be considered a liberal interpretation of the CAN. Analysis 2 uses group maps for brain regions associated with activity in both the sympathetic and parasympathetic divisions of the ANS. Analysis 3 uses group maps for brain regions supporting ANS outflow for all three task categories (somatosensory-motor, affective, cognitive).

The results of Analysis 3 were calculated as a prerequisite for conjunction analyses (see below) and therefore not reported. In addition, for Analyses 1 and 2, we were interested in hemispheric differences, which we assessed by converting the thresholded ALE maps to $z$ statistic maps and contrasting the original map with its right-left flipped version. A $p$ value of 0.05 was considered significant. Note that we did not apply a correction for multiple comparisons to the laterality tests. This is because we had already established a significant activation in these regions, and the right-left difference is orthogonal to the bilateral effect per se.

Conjunction analyses. Using the results of the analyses detailed above, we also performed two conjunction analyses. These analyses used the conjunction null hypothesis (Nichols et al., 2005) and tested for brain areas that were activated in all conditions under consideration. We calculated the overlap of thresholded ALE maps, again applying a minimum cluster size of $100 \mathrm{~mm}^{3}$. The two conjunction analyses were as follows: Analysis 4 used conjunction analyses for each task type and each ANS division to identify sympathetic and parasympathetic contributions to CAN modulatory regions observed for different tasks. Analysis 5 used a conjunction across all three task categories to identify regions mediating autonomic activity regardless of the task used to stimulate ANS outflow.
This provided a more specific interpretation of the CAN compared to Analysis 1.

\section{Results}

The pooled analysis of all studies (Analysis 1, 43 studies, 615 subjects, 571 foci) revealed a widespread network of cortical and subcortical regions consisting of ACC; midcingulate cortex (MCC); ventral posterior cingulate cortex; thalamus; bilateral anterior (aINS), left posterior (pINS), and right frontal insular cortices; vmPFC; bilateral amygdala; right hippocampal formation (HF); hypothalamus; midbrain and brainstem regions; and a lateral parietal area comprising parts of the right angular (AG) 
Table 4. ALE clusters of the conjunction analyses for the three task types and the two ANS divisions showing sympathetic and parasympathetic contributions to CAN modulatory regions observed for different tasks

\begin{tabular}{|c|c|c|c|c|c|c|}
\hline \multirow[b]{2}{*}{ Anatomical region } & \multirow[b]{2}{*}{$\mathrm{L} / \mathrm{R}$} & \multirow[b]{2}{*}{ Size $\left(\mathrm{mm}^{3}\right)$} & \multirow[b]{2}{*}{ Max. ALE score } & \multicolumn{3}{|c|}{ MNI coordinates (in mm) } \\
\hline & & & & $x$ & $y$ & $z$ \\
\hline \multicolumn{7}{|l|}{ Cognitive and sympathetic } \\
\hline Midcingulate cortex, paracingulate cortex, supplementary motor area & $L / R$ & 7960 & 0.0120 & -2 & 16 & 44 \\
\hline Anterior insula, frontal operculum, temporal pole & $\mathrm{R}$ & 1752 & 0.0078 & 48 & 18 & -6 \\
\hline Cerebellum (lobulus crus I) & $\mathrm{L}$ & 1648 & 0.0106 & -46 & -64 & -26 \\
\hline Secondary somatosensory cortex, posterior insula & $\mathrm{L}$ & 1576 & 0.0092 & -38 & -12 & 12 \\
\hline Ventromedial prefrontal cortex, subgenual anterior cingulate cortex & $\mathrm{L} / \mathrm{R}$ & 1352 & 0.0088 & -4 & 38 & -16 \\
\hline Superior parietal lobule, supramarginal gyrus & L & 1304 & 0.0077 & -32 & -48 & 42 \\
\hline Amygdala & $\mathrm{L}$ & 656 & 0.0051 & -22 & -8 & -16 \\
\hline \multicolumn{7}{|l|}{ Cognitive and parasympathetic } \\
\hline Amygdala & $\mathrm{L}$ & 480 & 0.0051 & -22 & -8 & -16 \\
\hline Anterior insula & $\mathrm{R}$ & 400 & 0.0054 & 34 & 20 & 4 \\
\hline \multicolumn{7}{|l|}{ Affective and sympathetic } \\
\hline Amygdala & $\mathrm{L}$ & 3184 & 0.0114 & -20 & -8 & -12 \\
\hline Supramarginal gyrus, primary somatosensory cortex & $\mathrm{R}$ & 2752 & 0.0089 & 48 & -26 & 44 \\
\hline Posterior midcingulate cortex & $\mathrm{L} / \mathrm{R}$ & 2616 & 0.0084 & 4 & 0 & 48 \\
\hline Anterior insula, ventrolateral prefrontal cortex & $\mathrm{R}$ & 2496 & 0.0103 & 38 & 24 & -20 \\
\hline Secondary somatosensory cortex, posterior insula, putamen & $\mathrm{L}$ & 1872 & 0.0084 & -18 & -16 & 18 \\
\hline Thalamus (mediodorsal nucleus) & $\mathrm{L}$ & 968 & 0.0072 & -6 & -12 & 4 \\
\hline Supramarginal gyrus, angular gyrus, superior parietal lobule & $\mathrm{R}$ & 624 & 0.0067 & 38 & -46 & 36 \\
\hline \multicolumn{7}{|l|}{ Affective and parasympathetic } \\
\hline Amygdala & $\mathrm{L}$ & 3920 & 0.0124 & -20 & -6 & -18 \\
\hline Hippocampal formation, amygdala & $\mathrm{R}$ & 2840 & 0.0095 & 30 & -22 & -16 \\
\hline Anterior insula, caudate & $\mathrm{L}$ & 2192 & 0.0071 & -30 & 26 & 8 \\
\hline Anterior insula & $\mathrm{R}$ & 2184 & 0.0071 & 44 & 12 & 6 \\
\hline \multicolumn{7}{|l|}{ Somatosensory-motor and sympathetic } \\
\hline Midcingulate cortex & $\mathrm{L} / \mathrm{R}$ & 5392 & 0.0165 & 2 & 12 & 40 \\
\hline Amygdala, hippocampus & $\mathrm{L}$ & 944 & 0.0082 & -18 & -8 & -16 \\
\hline Supramarginal gyrus, angular gyrus & $\mathrm{R}$ & 784 & 0.0080 & 58 & -40 & 22 \\
\hline Supplementary motor area & $\mathrm{L}$ & 704 & 0.0086 & -10 & 4 & 62 \\
\hline Secondary somatosensory cortex, posterior insula & $\mathrm{L}$ & 664 & 0.0086 & -34 & -20 & 14 \\
\hline Red nucleus, periaqueductal gray & $\mathrm{L} / \mathrm{R}$ & 624 & 0.0057 & -2 & -16 & -8 \\
\hline Ventromedial prefrontal cortex, pregenual/subgenual anterior cingulate cortex & $\mathrm{L}$ & 464 & 0.0061 & -4 & 38 & -12 \\
\hline Ventromedial prefrontal cortex, pregenual/subgenual anterior cingulate cortex & $\mathrm{R}$ & 352 & 0.0059 & 8 & 42 & -6 \\
\hline \multicolumn{7}{|l|}{ Somatosensory-motor and parasympathetic } \\
\hline Precuneus, dorsal posterior cingulate cortex & $L / R$ & 2856 & 0.0076 & -6 & -42 & 32 \\
\hline Amygdala, ventral tegmental area, hypothalamus & $\mathrm{L}$ & 2176 & 0.0083 & -18 & -8 & -16 \\
\hline Anterior insula & $\mathrm{R}$ & 1984 & 0.0072 & 40 & 2 & 12 \\
\hline Anterior insula & $\mathrm{L}$ & 1304 & 0.0072 & -40 & 0 & 12 \\
\hline Angular gyrus & $\mathrm{R}$ & 1104 & 0.0063 & 58 & -50 & 22 \\
\hline Hippocampal formation & $\mathrm{R}$ & 1024 & 0.0055 & 22 & -12 & -20 \\
\hline Cerebellum (lobulus vermis VI) & $\mathrm{R}$ & 144 & 0.0055 & -2 & -72 & -24 \\
\hline
\end{tabular}

There were 11 studies, 145 subjects, and 165 foci for cognitive stimuli/tasks; 12 studies, 230 subjects, and 107 foci for affective stimuli/tasks; 13 studies, 136 subjects, and 245 foci for somatosensory-motor stimuli/tasks; 19 studies, 296 subjects, and 172 foci for EDA; and 8 studies, 106 subjects, and 94 foci for HFHRF. L, Left; R, right.

and supramarginal gyrus (SMG) (Fig. 1; Table 2). Hemispheric differences were found for the amygdala (left $>$ right).

Brain areas associated with sympathetic regulation (Analysis 2, 19 studies, 296 subjects, 172 foci) were ACC, MCC, paracingulate cortex, thalamus, right aINS, left pINS, vmPFC, left amygdala, left HF, right SMG, left primary (S1) and secondary (S2) somatosensory cortex, supplementary motor area (SMA), bilateral superior parietal lobule (SPL), ventrolateral (vlPFC) and right dorsolateral (dlPFC) prefrontal cortices, midbrain, and left cerebellum (Fig. 2; Table 3). No hemispheric differences were found.

In contrast, regions of parasympathetic regulation (Analysis 3, 8 studies, 106 subjects, 94 foci) comprised the dorsal posterior cingulate cortex (dPCC)/precuneus, bilateral aINS, left amygdala, right HF, right SMG/AG, left primary motor cortex, right medial and superior temporal gyri and left temporal pole, hypothalamus, midbrain, and left cerebellum (Fig. 2; Table $3)$. Here, once again, hemispheric differences were found for the amygdala (left $>$ right).
We also investigated conjunctions of tasks and ANS divisions [Analysis 4, using foci for cognitive (11 studies, 145 subjects, 165 foci), affective (12 studies, 230 subjects, 107 foci), and somatosensory-motor ( 13 studies, 136 subjects, 245 foci), as well as foci reported for Analyses 2 and 3 above]. Regions associated with sympathetic outflow included MCC, right aINS, left pINS, vmPFC/subgenual ACC (sgACC), left SPL, left amygdala, and left cerebellum for cognitive tasks; MCC, right aINS, left pINS, right SMG/AG, left amygdala, and left thalamus for affective tasks; and MCC, left pINS, vmPFC/sgACC, right SMG/AG, left amygdala/ $\mathrm{HF}$, and periaqueductal gray for somatosensory-motor tasks (Fig. 3; Table 4). For parasympathetic outflow, we found right aINS and left amygdala to be associated with cognitive tasks; bilateral aINS, left caudate, left amygdala, and right HF with affective tasks; and dPCC, bilateral aINS, right AG, left amygdala, right $\mathrm{HF}$, and ventral tegmental area for somatosensory-motor tasks.

Conjunction analysis of all task categories (Analysis 5) showed four regions to be consistently involved in autonomic regulation 

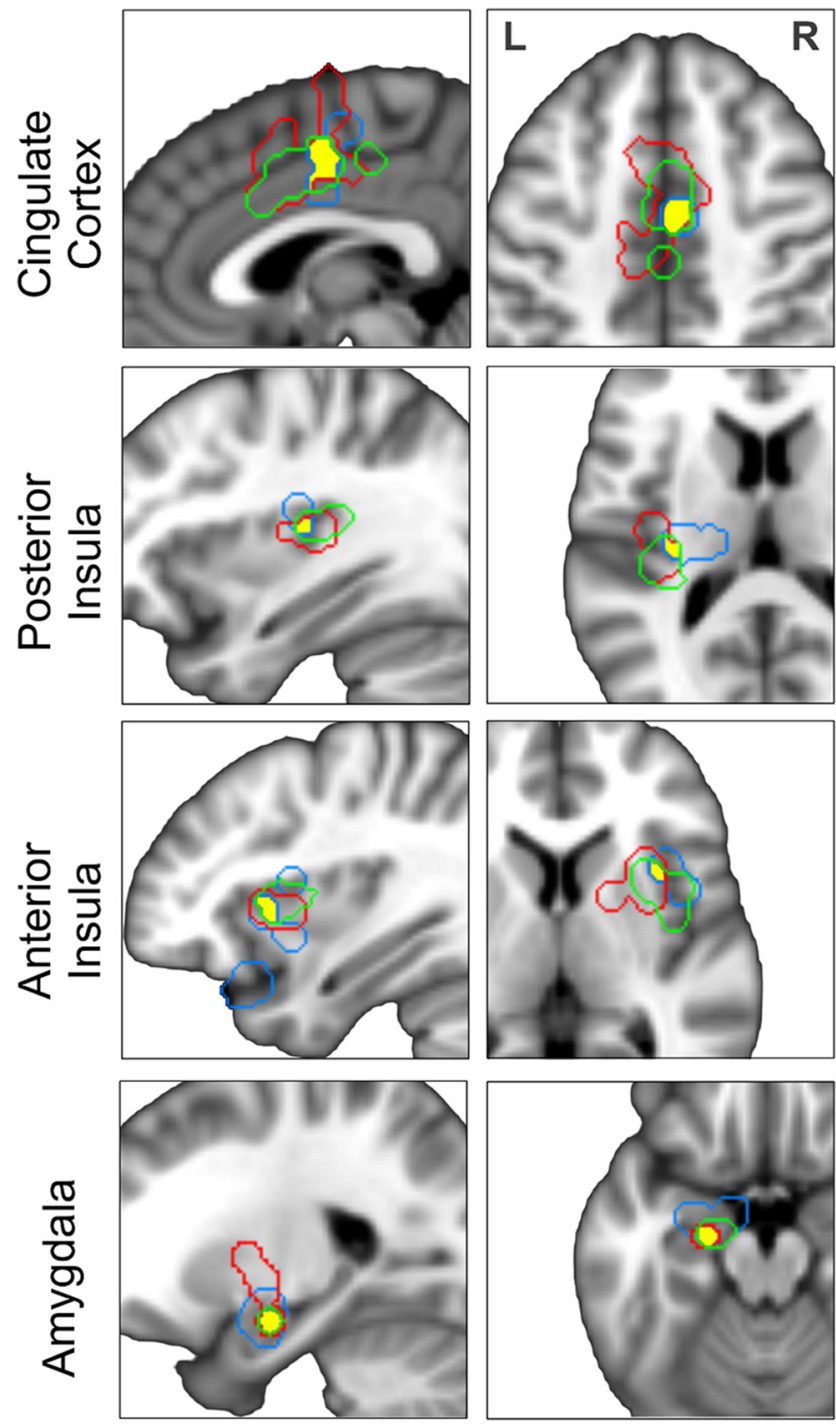

Affective

Cognitive

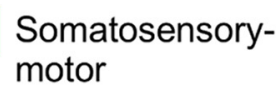

Overlap motor

Figure 4. Core regions of the CAN as revealed by a conjunction analysis of autonomic modulatory regions across the three task categories. L, Left; $R$, right.

across tasks (Fig. 4), namely, the posterior MCC (MNI coordinates, $x=4, y=0, z=48)$, left amygdala $(-22,-8,-16)$, right aINS $(34,20,4)$, and left pINS $(-32,-18,12)$. It should also be noted that a cluster in the pregenual anterior cingulate cortex extending to the vmPFC was just under threshold for the affective task category and thus for the conjunction map across all tasks.

\section{Discussion}

Several regions identified by our human neuroimaging metaanalysis are fully consistent with a central autonomic network as proposed by many authors based on the results of animal experiments (Cechetto and Saper, 1990; Benarroch, 1993; Verberne and Owens, 1998; Saper, 2002). For instance, the results of the pooled analysis (Fig. 1) show anterior and midcingulate cortices, insula, ventromedial prefrontal cortex, mediodorsal thalamus, amygdala, HF, and hypothalamus as component regulatory areas of this network. Other regions, however, such as the angular gyrus, pulvinar, and precuneus, have been less often reported in this context and should be explored in more detail by future studies to better understand their role in regulating the ANS.

Separate analyses of the brain regions supporting sympathetic and parasympathetic regulation (Fig. 2) revealed largely divergent networks. Sympathetic regulation mainly involved prefrontal, anterior, and midcingulate, right ventral anterior insular and left posterior insular cortices, while parasympathetic regulation involved PCC, lateral temporal cortices, bilateral dorsal aINS, and HF. Importantly, the few regions that showed a dual role as both sympathetic and parasympathetic regulation centers included the left amygdala, right inferior parietal lobule, and a small area in right aINS, where the ventral sympathetic and dorsal parasympathetic clusters overlapped.

Concerning task specificity, our analysis revealed divergent networks for each task category (Fig. 3). We found a predominance of sympathetic regions in cognitive tasks consistent with the important role the sympathetic nervous system plays in cognitive stress (Anderson et al., 1991). Affective and somatosensory-motor tasks, in contrast, showed a more balanced contribution of sympathetic and parasympathetic regions. While each network had its distinctive features, we were more interested in the consensus regions mediating autonomic activity across tasks. As the pooled analysis (Fig. 1) detected any region reported by a sufficient number of studies, regardless of task, we conducted a conjunction analysis of the three task categories to identify a more specific set of regions. This analysis revealed four regions, which we posit to be the core of the central autonomic network (Fig. 4). They comprised the MCC, the right aINS, the left pINS, and the left amygdala. Among these, the amygdala was the only region with both sympathetic and parasympathetic regulatory function.

The amygdala is best known for its role in emotional processing, especially in the evaluation of aversive stimuli (Weiskrantz, 1956; LeDoux, 1992), which is consistent with a strong linkage to sympathetic regulation. More recent work has focused on determining the amygdala's role in regulation or modulation of cognitive functions, including attention, perception, and explicit memory (Ledoux, 2007). Its involvement in parasympathetic regulation, however, is an interesting and new finding that may reflect the need for balancing both increased sympathetic and decreased parasympathetic outflow in response to aversive stimuli. Furthermore, left lateralization of amygdala function, as noted in our results, has been shown before in the context of emotion processing (Morris et al., 1998; Wager et al., 2003), especially, when subjects were aware of the presented stimuli. Left dominance was also described by Thayer et al. (2012) in their meta-analysis of HRV-related brain activity.

The insula is a functionally heterogeneous structure and has been shown previously to consist of at least three functional subregions exhibiting differential connectivity with the cingulate cortex (Deen et al., 2011). Its involvement in autonomic functions and interoceptive feedback has been studied extensively (Critchley et al., 2000a; Craig, 2002). Our results suggest different autonomic roles for left and right, anterior and posterior, as well as dorsal and ventral portions of the insula. While the dorsal aINS was bilaterally associated with parasympathetic regulation, the right ventral aINS showed sympathetic predominance extending to the adjacent frontal operculum (Fig. 2). Interestingly, previous meta-analyses found that while dorsal aINS was associated with cognitive processing, ventral aINS was associated with affective/ emotional processing (Kurth et al., 2010). Moreover, although no explicit lateralization was found in our analysis for regions other 
than amygdala, the results of Analyses 2 and 4 support previous theories of functional specialization of the right anterior insula as a sympathetic regulatory center (Craig, 2005; Cechetto and Shoemaker, 2009). However, as some authors noted for the case of emotional responses (Hagemann et al., 2003; Wager et al., 2003), the hypothesis of a more generalized left/right dichotomy with respect to forebrain (and insular) (Craig, 2005) specialization in parasympathetic/sympathetic regulation is probably untenable.

Like the insula, the cingulate cortex is a functionally and structurally heterogeneous structure (Vogt et al., 1992). Three of the four major subregions that have been proposed to describe its different functions were found to be involved in autonomic regulation by our study, namely, the ACC, MCC, and PCC, with the largest cluster in the MCC. Anterior regions (ACC, MCC) were primarily associated with sympathetic, while posterior regions (PCC) were associated with parasympathetic outflow. Interestingly, the overlap of cingulate clusters between our different ANS-linked task categories was surprisingly small. The only region that was involved in ANS regulation for all tasks was the posterior MCC, an area usually reported in the context of cutaneous nociception (Vogt, 2005), response selection, and skeletomotor body orientation (Devinsky et al., 1995).

Our results can also be interpreted from the perspective of known large-scale brain networks. For instance, Fox et al. (2005) suggested in their influential paper that the activity of the brain at rest can be divided into a task-negative and a task-positive network that are temporally anticorrelated. The former is now widely known as the default mode network (DMN) (Raichle et al., 2001; Buckner et al., 2008); the latter consists of at least three subnetworks that vary in nomenclature. For example, Power et al. (2011) differentiated a dorsal attention network, a frontoparietal control network, and a cingulo-opercular task control system. Similarly, Seeley et al. (2007) differentiated the task-positive network into a central executive network (Selemon and GoldmanRakic, 1988; Beckmann et al., 2005) and a salience network (Mufson and Mesulam, 1982; Seeley et al., 2007). As Figure 2 and Table 3 demonstrate, most of the DMN regions involved in autonomic processing (PCC, LTC, HF, and IPL) show a predilection toward parasympathetic regulation. A notable exception was the vmPFC, often considered a DMN region. However, the ventral portion of the vmPFC that contains a significant sympathetic regulation cluster has been suggested to belong to a separate "limbic" network rather than the DMN itself (Yeo et al., 2011). In stark contrast, most regions of the task-positive networks involved in autonomic regulation showed sympathetic predominance (dlPFC, vlPFC, aINS, MCC, and SPL). Together, these findings support divergent CAN subregions for regulating the sympathetic versus parasympathetic divisions of the ANS (Cannon, 1929; Recordati, 2003). The parasympathetic system prepares the body for internal physiological activity, thus the connection with the DMN, whose functional correlates are usually ascribed to self-referential cognition (Buckner et al., 2008). The sympathetic nervous system, in contrast, orchestrates bodily functions aimed at interacting with the external environment, which explains the colocalization of sympathetic regulatory regions with task-positive (sub)networks.

Interestingly, a linkage between DMN activity and autonomic regulation has been described in several previous studies (Nagai et al., 2004a; Wong et al., 2007; Dhond et al., 2008). Parasympatheticmodulatory brain regions were identified in our analysis by studies adopting HF-HRV, a cardiovagal metric. Previous studies have found that posterior portions of the DMN are particularly sensitive to physiological (cardiorespiratory) artifact correction algorithms (Khalili-Mahani et al., 2013), underscoring the important neurophysiological role of brain regions such as the PCC in cardioautonomic modulation.

In general, the interdependence of brain regions previously thought to subserve cognitive or executive associative brain functions with those found by our study as relating to central autonomic modulation raises several provocative possibilities. For instance, a nonnegligible component of the neuronal activity previously attributed in neuroimaging experiments to cognitive or executive control functions may instead (or in addition) signal medullary premotor nuclei underlying autonomic processing that calibrates bodily reactions with contextually adaptive behavior appropriate for these "higher" order functions (Thayer and Lane, 2000; Critchley, 2005).

Some limitations need to be discussed. Our meta-analysis did not differentiate between increases and decreases, or positive and negative correlations, of the PET and fMRI signals associated with sympathetic/parasympathetic activity. A more precise approach would be to form four categories, one for each combination of BOLD activation/deactivation and increase/decrease of the autonomic metric. However, given the low number of available studies, this would have precluded a meaningful metaanalysis at this time. Furthermore, our choice of EDA as the sympathetic metric and HF-HRV as the parasympathetic metric cannot rule out the possibility that some of our results were influenced by organ-specific autonomic systems (i.e., skin vs heart). Finally, although we chose to exclude studies from our meta-analysis that recorded brain imaging and ANS data in different experimental sessions (King et al., 1999; Dalton et al., 2005; Macefield et al., 2007; Wong et al., 2007; Burton et al., 2009; Sander et al., 2010; Gianaros et al., 2012), it should be noted that many of these studies reported brain areas (amygdala, cingulate, insular, and prefrontal cortices, etc.) consistent with our description of the central autonomic network.

In conclusion, our human neuroimaging meta-analysis identified a set of consistently activated brain regions, comprising the left amygdala, right anterior and left posterior insular, and midcingulate cortices that form the core of the CAN. The sympathetic and parasympathetic divisions have largely divergent regulatory networks differentially involved in affective, cognitive, and somatosensory-motor tasks.

\section{References}

Acharya UR, Joseph KP, Kannathal N, Lim CM, Suri JS (2006) Heart rate variability: a review. Med Bio Eng Comput 44:1031-1051. CrossRef

Anderson EA, Sinkey CA, Mark AL (1991) Mental stress increases sympathetic nerve activity during sustained baroreceptor stimulation in humans. Hypertension 17:III43-III49. CrossRef Medline

Beckmann CF, DeLuca M, Devlin JT, Smith SM (2005) Investigations into resting-state connectivity using independent component analysis. Philos Trans R Soc Lond B Biol Sci 360:1001-1013. CrossRef Medline

Beissner F, Deichmann R, Henke C, Bär KJ (2012) Acupuncture: deep pain with an autonomic dimension? Neuroimage 60:653-660. CrossRef Medline

Benarroch EF (1993) The central autonomic network: functional organization, dysfunction, and perspective. Mayo Clin Proc 68:988-1001. CrossRef Medline

Buckner RL, Andrews-Hanna JR, Schacter DL (2008) The brain's default network: anatomy, function, and relevance to disease. Ann N Y Acad Sci 1124:1-38. CrossRef

Burton AR, Birznieks I, Bolton PS, Henderson LA, Macefield VG (2009) Effects of deep and superficial experimentally induced acute pain on muscle sympathetic nerve activity in human subjects. J Physiol 587:183-193. CrossRef Medline

Cannon W (1929) Organization for physiological homeostasis. Physiol Rev 9:399-431.

Cechetto DF, Saper CB (1990) Role of the cerebral cortex in autonomic 
function. Central Regulation of Autonomic Functions (Loewy AD, Spyer KM, eds.), pp 208-223. Oxford: Oxford UP.

Cechetto DF, Shoemaker JK (2009) Functional neuroanatomy of autonomic regulation. Neuroimage 47:795-803. CrossRef Medline

Craig AD (2002) How do you feel? Interoception: the sense of the physiological condition of the body. Nat Rev Neurosci 3:655-666. Medline

Craig AD (2005) Forebrain emotional asymmetry: a neuroanatomical basis? Trends Cogn Sci 9:566-571. CrossRef Medline

Critchley HD (2005) Neural mechanisms of autonomic, affective, and cognitive integration. J Comp Neurol 493:154-166. CrossRef Medline

Critchley HD, Corfield DR, Chandler MP, Mathias CJ, Dolan RJ (2000a) Cerebral correlates of autonomic cardiovascular arousal: a functional neuroimaging investigation in humans. J Physiol 523:259-270. CrossRef Medline

Critchley HD, Elliott R, Mathias CJ, Dolan RJ (2000b) Neural activity relating to generation and representation of galvanic skin conductance responses: a functional magnetic resonance imaging study. J Neurosci 20:3033-3040. Medline

Critchley HD, Mathias CJ, Josephs O, O’Doherty J, Zanini S, Dewar BK, Cipolotti L, Shallice T, Dolan RJ (2003) Human cingulate cortex and autonomic control: converging neuroimaging and clinical evidence. Brain 126:2139-2152. CrossRef Medline

Critchley HD, Tang J, Glaser D, Butterworth B, Dolan RJ (2005) Anterior cingulate activity during error and autonomic response. Neuroimage 27: 885-895. CrossRef Medline

Critchley HD, Nagai Y, Gray MA, Mathias CJ (2011) Dissecting axes of autonomic control in humans: Insights from neuroimaging. Auton Neurosci 161:34-42. CrossRef Medline

Dalton KM, Kalin NH, Grist TM, Davidson RJ (2005) Neural-cardiac coupling in threat-evoked anxiety. J Cogn Neurosci 17:969-980. CrossRef Medline

Damasio AR (1998) Emotion in the perspective of an integrated nervous system. Brain Res Brain Res Rev 26:83-86. CrossRef Medline

Deen B, Pitskel NB, Pelphrey KA (2011) Three systems of insular functional connectivity identified with cluster analysis. Cereb Cortex 21:1498-1506. CrossRef Medline

Devinsky O, Morrell MJ, Vogt BA (1995) Contributions of anterior cingulate cortex to behaviour. Brain 118:279-306. CrossRef Medline

Dhond RP, Yeh C, Park K, Kettner N, Napadow V (2008) Acupuncture modulates resting state connectivity in default and sensorimotor brain networks. Pain 136:407-418. CrossRef Medline

Eickhoff SB, Laird AR, Grefkes C, Wang LE, Zilles K, Fox PT (2009) Coordinate-based activation likelihood estimation meta-analysis of neuroimaging data: a random-effects approach based on empirical estimates of spatial uncertainty. Hum Brain Mapp 30:2907-2926. CrossRef Medline

Evans KC, Dougherty DD, Schmid AM, Scannell E, McCallister A, Benson H, Dusek JA, Lazar SW (2009) Modulation of spontaneous breathing via limbic/paralimbic-bulbar circuitry: An event-related fMRI study. Neuroimage 47:961-971. CrossRef Medline

Fechir M, Gamer M, Blasius I, Bauermann T, Breimhorst M, Schlindwein P, Schlereth T, Birklein F (2010a) Functional imaging of sympathetic activation during mental stress. Neuroimage 50:847-854. CrossRef Medline

Fechir M, Klega A, Buchholz HG, Pfeifer N, Balon S, Schlereth T, Geber C, Breimhorst M, Maihöfner C, Birklein F, Schreckenberger M (2010b) Cortical control of thermoregulatory sympathetic activation. Eur J Neurosci 31:2101-2111. CrossRef Medline

Fox MD, Snyder AZ, Vincent JL, Corbetta M, Van Essen DC, Raichle ME (2005) The human brain is intrinsically organized into dynamic, anticorrelated functional networks. Proc Natl Acad Sci U S A 102:9673-9678. CrossRef Medline

Fredrikson M, Wik G, Fischer H, Andersson J (1995) Affective and attentive neural networks in humans: a PET study of Pavlovian conditioning. Neuroreport 7:97-101. Medline

Friston KJ, Worsley KJ, Frackowiak RS, Mazziotta JC, Evans AC (1994) Assessing the significance of focal activations using their spatial extent. Hum Brain Mapp 1:210-220.

Gamer M, Bauermann T, Stoeter P, Vossel G (2007) Covariations among fMRI, skin conductance, and behavioral data during processing of concealed information. Hum Brain Mapp 28:1287-1301. CrossRef Medline

Gianaros PJ, Onyewuenyi IC, Sheu LK, Christie IC, Critchley HD (2012) Brain systems for baroreflex suppression during stress in humans. Hum Brain Mapp 33:1700-1716. Medline
Goswami R, Frances MF, Shoemaker JK (2011) Representation of somatosensory inputs within the cortical autonomic network. Neuroimage 54: 1211-1220. CrossRef Medline

Gray MA, Beacher FD, Minati L, Nagai Y, Kemp AH, Harrison NA, Critchley HD (2012) Emotional appraisal is influenced by cardiac afferent information. Emotion 12:180-191. CrossRef Medline

Hagemann D, Waldstein SR, Thayer JF (2003) Central and autonomic nervous system integration in emotion. Brain Cogn 52:79-87. CrossRef Medline

Harrison NA, Gray MA, Critchley HD (2009) Dynamic pupillary exchange engages brain regions encoding social salience. Soc Neurosci 4:233-243. CrossRef Medline

Harrison NA, Gray MA, Gianaros PJ, Critchley HD (2010) The embodiment of emotional feelings in the brain. J Neurosci 30:12878-12884. CrossRef Medline

Ito $\mathrm{H}$, Yokoyama I, Tamura Y, Kinoshita T, Hatazawa J, Kawashima R, Iida $\mathrm{H}$ (2002) Regional changes in human cerebral blood flow during dipyridamole stress: neural activation in the thalamus and prefrontal cortex. Neuroimage 16:788-793. CrossRef Medline

Jänig W (2008) Integrative action of the autonomic nervous system: neurobiology of homeostasis. Cambridge, UK: Cambridge UP.

Khalili-Mahani N, Chang C, van Osch MJ, Veer IM, van Buchem MA, Dahan A, Beckmann CF, van Gerven JM, Rombouts SA (2013) The impact of "physiological correction" on functional connectivity analysis of pharmacological resting state fMRI. Neuroimage 65:499-510. Medline

Kimmerly DS, O'Leary DD, Menon RS, Gati JS, Shoemaker JK (2005) Cortical regions associated with autonomic cardiovascular regulation during lower body negative pressure in humans. J Physiol 569:331-345. CrossRef Medline

King AB, Menon RS, Hachinski V, Cechetto DF (1999) Human forebrain activation by visceral stimuli. J Comp Neurol 413:572-582. CrossRef Medline

Knight DC, Nguyen HT, Bandettini PA (2005) The role of the human amygdala in the production of conditioned fear responses. Neuroimage 26:1193-1200. CrossRef Medline

Koelsch S, Remppis A, Sammler D, Jentschke S, Mietchen D, Fritz T, Bonnemeier H, Siebel WA (2007) A cardiac signature of emotionality. Eur J Neurosci 26:3328-3338. CrossRef Medline

Kozel FA, Johnson KA, Laken SJ, Grenesko EL, Smith JA, Walker J, George MS (2009) Can simultaneously acquired electrodermal activity improve accuracy of fMRI detection of deception? Soc Neurosci 4:510-517. CrossRef Medline

Kuniecki M, Urbanik A, Sobiecka B, Kozub J, Binder M (2003) Central control of heart rate changes during visual affective processing as revealed by fMRI. Acta Neurobiol Exp (Wars) 63:39-48. Medline

Kurth F, Zilles K, Fox PT, Laird AR, Eickhoff SB (2010) A link between the systems: functional differentiation and integration within the human insula revealed by meta-analysis. Brain Struct Funct 214:519-534. CrossRef Medline

Lagopoulos J, Malhi GS (2007) A functional magnetic resonance imaging study of emotional Stroop in euthymic bipolar disorder. Neuroreport 18:1583-1587. CrossRef Medline

Lancaster JL, Tordesillas-Gutiérrez D, Martinez M, Salinas F, Evans A, Zilles K, Mazziotta JC, Fox PT (2007) Bias between MNI and Talairach coordinates analyzed using the ICBM152 brain template. Hum Brain Mapp 28:1194-1205. CrossRef Medline

Langley JN (1903) The autonomic nervous system. Brain 26:1-26. CrossRef LeDoux J (2007) The amygdala. Curr Biol 17:868-874.

LeDoux JE (1992) Brain mechanisms of emotion and emotional learning. Curr Opin Neurobiol 2:191-197. CrossRef Medline

Lemche E, Giampietro VP, Surguladze SA, Amaro EJ, Andrew CM, Williams SC, Brammer MJ, Lawrence N, Maier MA, Russell TA, Simmons A, Ecker C, Joraschky P, Phillips ML (2006) Human attachment security is mediated by the amygdala: evidence from combined fMRI and psychophysiological measures. Hum Brain Mapp 27:623-635. CrossRef Medline

Macefield VG, Gandevia SC, Henderson LA (2007) Discrete changes in cortical activation during experimentally induced referred muscle pain: a single-trial fMRI study. Cereb Cortex 17:2050-2059. Medline

Macey KE, Macey PM, Woo MA, Henderson LA, Frysinger RC, Harper RK, Alger JR, Yan-Go F, Harper RM (2006) Inspiratory loading elicits aberrant fMRI signal changes in obstructive sleep apnea. Respir Physiol Neurobiol 151:44-60. CrossRef Medline 
Maihöfner C, Seifert F, Decol R (2011) Activation of central sympathetic networks during innocuous and noxious somatosensory stimulation. Neuroimage 55:216-224. CrossRef Medline

Marci CD, Glick DM, Loh R, Dougherty DD (2007) Autonomic and prefrontal cortex responses to autobiographical recall of emotions. Cogn Affect Behav Neurosci 7:243-250. CrossRef Medline

Matsunaga M, Isowa T, Kimura K, Miyakoshi M, Kanayama N, Murakami H, Fukuyama S, Shinoda J, Yamada J, Konagaya T, Kaneko H, Ohira H (2009) Associations among positive mood, brain, and cardiovascular activities in an affectively positive situation. Brain Res 1263:93-103. CrossRef Medline

Mériau K, Wartenburger I, Kazzer P, Prehn K, Villringer A, van der Meer E, Heekeren HR (2009) Insular activity during passive viewing of aversive stimuli reflects individual differences in state negative affect. Brain Cogn 69:73-80. CrossRef Medline

Mobascher A, Brinkmeyer J, Warbrick T, Musso F, Wittsack HJ, Stoermer R, Saleh A, Schnitzler A, Winterer G (2009) Fluctuations in electrodermal activity reveal variations in single trial brain responses to painful laser stimuli: a fMRI/EEG study. Neuroimage 44:1081-1092. CrossRef Medline

Morris JS, Öhman A, Dolan RJ (1998) Conscious and unconscious emotional learning in the human amygdala. Nature 393:467-470. CrossRef Medline

Mufson EJ, Mesulam MM (1982) Insula of the Old World monkey. II: afferent cortical input and comments on the claustrum. J Comp Neurol 212:23-37. CrossRef Medline

Nagai Y, Critchley HD, Featherstone E, Trimble MR, Dolan RJ (2004a) Activity in ventromedial prefrontal cortex covaries with sympathetic skin conductance level: a physiological account of a "default mode" of brain function. Neuroimage 22:243-251. CrossRef Medline

Nagai Y, Critchley HD, Featherstone E, Fenwick PB, Trimble MR, Dolan RJ (2004b) Brain activity relating to the contingent negative variation: an fMRI investigation. Neuroimage 21:1232-1241. CrossRef Medline

Napadow V, Dhond R, Conti G, Makris N, Brown EN, Barbieri R (2008) Brain correlates of autonomic modulation: combining heart rate variability with fMRI. Neuroimage 42:169-177. CrossRef Medline

Napadow V, Lee J, Kim J, Cina S, Maeda Y, Barbieri R, Harris RE, Kettner N, Park K (2012) Brain correlates of phasic autonomic response to acupuncture stimulation: an event-related fMRI study. Hum Brain Mapp. Advance online publication. doi: 10.1002/hbm.22091. CrossRef Medline

Nichols T, Brett M, Andersson J, Wager T, Poline JB (2005) Valid conjunction inference with the minimum statistic. Neuroimage 25:653660. CrossRef Medline

Nicotra A, Critchley HD, Mathias CJ, Dolan RJ (2006) Emotional and autonomic consequences of spinal cord injury explored using functional brain imaging. Brain 129: 718-728. CrossRef Medline

Nugent AC, Bain EE, Thayer JF, Sollers JJ 3rd, Drevets WC (2011) Heart rate variability during motor and cognitive tasks in females with major depressive disorder. Psychiatry Res 191:1-8. CrossRef Medline

Ohira H, Fukuyama S, Kimura K, Nomura M, Isowa T, Ichikawa N, Matsunaga M, Shinoda J, Yamada J (2009) Regulation of natural killer cell redistribution by prefrontal cortex during stochastic learning. Neuroimage 47:897-907. CrossRef Medline

Petrovic P, Petersson KM, Hansson P, Ingvar M (2004) Brainstem involvement in the initial response to pain. Neuroimage 22:995-1005. CrossRef Medline

Piché M, Arsenault M, Rainville P (2010) Dissection of perceptual, motor and autonomic components of brain activity evoked by noxious stimulation. Pain 149:453-462. CrossRef Medline

Power JD, Cohen AL, Nelson SM, Wig GS, Barnes KA, Church JA, Vogel AC, Laumann TO, Miezin FM, Schlaggar BL, Petersen SE (2011) Functional network organization of the human brain. Neuron 72:665-678. CrossRef Medline

Raichle ME, MacLeod AM, Snyder AZ, Powers WJ, Gusnard DA, Shulman GL (2001) A default mode of brain function. Proc Natl Acad Sci U S A 98:676-682. CrossRef Medline

Recordati G (2003) A thermodynamic model of the sympathetic and parasympathetic nervous systems. Auton Neurosci 103:1-12. CrossRef Medline

Redouté J, Stoléru S, Grégoire MC, Costes N, Cinotti L, Lavenne F, Le Bars D, Forest MG, Pujol JF (2000) Brain processing of visual sexual stimuli in human males. Hum Brain Mapp 11:162-177. CrossRef Medline
Sander M, Macefield VG, Henderson LA (2010) Cortical and brain stem changes in neural activity during static handgrip and postexercise ischemia in humans. J Appl Physiol 108:1691-1700. CrossRef Medline

Saper CB (2002) The central autonomic nervous system: conscious visceral perception and autonomic pattern generation. Annu Rev Neurosci 25: 433-469. CrossRef Medline

Seeley WW, Menon V, Schatzberg AF, Keller J, Glover GH, Kenna H, Reiss AL, Greicius MD (2007) Dissociable intrinsic connectivity networks for salience processing and executive control. J Neurosci 27:2349 2356. CrossRef Medline

Selemon LD, Goldman-Rakic PS (1988) Common cortical and subcortical targets of the dorsolateral prefrontal and posterior parietal cortices in the rhesus monkey: evidence for a distributed neural network subserving spatially guided behavior. J Neurosci 8:4049-4068. Medline

Suzuki H, Watanabe S, Hamaguchi T, Mine H, Terui T, Kanazawa M, Oohisa N, Maruyama M, Yambe T, Itoh M, Fukudo S (2009) Brain activation associated with changes in heart rate, heart rate variability, and plasma catecholamines during rectal distention. Psychosom Med 71:619-626. CrossRef Medline

Thayer JF, Lane RD (2000) A model of neurovisceral integration in emotion regulation and dysregulation. J Affect Disord 61:201-216. CrossRef Medline

Thayer JF, Åhs F, Fredrikson M, Sollers JJ 3rd, Wager TD (2012) A metaanalysis of heart rate variability and neuroimaging studies: implications for heart rate variability as a marker of stress and health. Neurosci Biobehav Rev 36:747-756. Medline

Turkeltaub PE, Eden GF, Jones KM, Zeffiro TA (2002) Meta-analysis of the functional neuroanatomy of single-word reading: method and validation. Neuroimage 16:765-780. CrossRef Medline

Turkeltaub PE, Eickhoff SB, Laird AR, Fox M, Wiener M, Fox P (2012) Minimizing within-experiment and within-group effects in activation likelihood estimation meta-analyses. Hum Brain Mapp 33:1-13. CrossRef Medline

Urry HL, van Reekum CM, Johnstone T, Davidson RJ (2009) Individual differences in some (but not all) medial prefrontal regions reflect cognitive demand while regulating unpleasant emotion. Neuroimage 47:852863. CrossRef Medline

Venables P (1991) Autonomic activity. Ann N Y Acad Sci 620:191-207. CrossRef

Verberne AJ, Owens NC (1998) Cortical modulation of the cardiovascular system. Prog Neurobiol 54:149-168. CrossRef Medline

Vogt BA (2005) Pain and emotion interactions in subregions of the cingulate gyrus. Nat Rev Neurosci 6:533-544. CrossRef Medline

Vogt BA, Finch DM, Olson CR (1992) Functional heterogeneity in cingulate cortex: the anterior executive and posterior evaluative regions. Cereb Cortex 2:435-443. CrossRef Medline

Wager TD, Phan KL, Liberzon I, Taylor SF (2003) Valence, gender, and lateralization of functional brain anatomy in emotion: a meta-analysis of findings from neuroimaging. Neuroimage 19:513-531. CrossRef Medline

Weiskrantz L (1956) Behavioral changes associated with ablation of the amygdaloid complex in monkeys. J Comp Physiol Psychol 49:381391. CrossRef Medline

Wendt J, Lotze M, Weike AI, Hosten N, Hamm AO (2008) Brain activation and defensive response mobilization during sustained exposure to phobia-related and other affective pictures in spider phobia. Psychophysiology 45:205-215. CrossRef Medline

Williams LM, Phillips ML, Brammer MJ, Skerrett D, Lagopoulos J, Rennie C, Bahramali H, Olivieri G, David AS, Peduto A, Gordon E (2001) Arousal dissociates amygdala and hippocampal fear responses: evidence from simultaneous fMRI and skin conductance recording. Neuroimage 14: 1070-1079. CrossRef Medline

Williams LM, Brown KJ, Das P, Boucsein W, Sokolov EN, Brammer MJ, Olivieri G, Peduto A, Gordon E (2004) The dynamics of cortico-amygdala and autonomic activity over the experimental time course of fear perception. Brain Res Cogn Brain Res 21:114-123. CrossRef Medline

Wong SW, Massé N, Kimmerly DS, Menon RS, Shoemaker JK (2007) Ventral medial prefrontal cortex and cardiovagal control in conscious humans. Neuroimage 35:698-708. CrossRef Medline

Yeo BT, Krienen FM, Sepulcre J, Sabuncu MR, Lashkari D, Hollinshead M, Roffman JL, Smoller JW, Zöllei L, Polimeni JR, Fischl B, Liu H, Buckner RL (2011) The organization of the human cerebral cortex estimated by 
intrinsic functional connectivity. J Neurophysiol 106:1125-1165. CrossRef Medline

Ziegler G, Dahnke R, Yeragani VK, Bär KJ (2009) The relation of ventrome- dial prefrontal cortex activity and heart rate fluctuations at rest. Eur J Neurosci 30:2205-2210. CrossRef Medline 